OPEN ACCESS

Edited by:

Haiyang Tang,

University of Arizona, United States

Reviewed by:

James David West,

Vanderbilt University, United States

Pritesh Jain,

University of California, San Diego,

United States

*Correspondence:

Mengyang Liao

liaomengyang87@163.com

Zihua Zhou

zzhua2001@163.com

†These authors have contributed equally to this work

Specialty section:

This article was submitted to Cardiovascular Therapeutics, a section of the journal Frontiers in Cardiovascular Medicine

Received: 21 March 2021

Accepted: 17 May 2021

Published: 17 June 2021

Citation:

Dai Y, Qiu Z, Ma W, Li C, Chen X, Song X, Bai Z, Shi D, Zheng J, Pan G,

Liao Y, Liao M and Zhou Z (2021)

Long-Term Effect of a Vaccine

Targeting Endothelin-1 Receptor

Type A in Pulmonary Arterial

Hypertension

Front. Cardiovasc. Med. 8:683436

doi: 10.3389/fcvm.2021.683436

\section{Long-Term Effect of a Vaccine Targeting Endothelin-1 Receptor Type A in Pulmonary Arterial Hypertension}

\author{
Yong Dai ${ }^{1,2,3+}$, Zhihua Qiu ${ }^{1,2,3+}$, Wenrui Ma ${ }^{1,2,3+}$, Chang Li $^{1,2,3}$, Xiao Chen ${ }^{1,2,3}$, \\ Xiaoxiao Song ${ }^{1,2,3}$, Zeyang Bai ${ }^{1,2,3}$, Dingyang Shi ${ }^{1,2,3}$, Jiayu Zheng ${ }^{1,2,3}$, Guangwei Pan ${ }^{1,2,3}$, \\ Yuhua Liao ${ }^{1,2,3}$, Mengyang Liao ${ }^{1,2,3 *}$ and Zihua Zhou ${ }^{1,2,3 *}$ \\ ${ }^{1}$ Department of Cardiology, Union Hospital, Tongji Medical College, Huazhong University of Science and Technology, Wuhan, \\ China, ${ }^{2}$ Institute of Cardiology, Union Hospital, Tongji Medical College, Huazhong University of Science and Technology, \\ Wuhan, China, ${ }^{3}$ Key Lab of Molecular Biological Targeted Therapies of the Ministry of Education, Union Hospital, Tongji \\ Medical College, Huazhong University of Science and Technology, Wuhan, China
}

Background: Previously, we invented a therapeutic vaccine targeting the endothelin-A receptor (termed ETRQ $\beta$-002). ETRQ $\beta$-002 successfully prevented the remodeling of pulmonary arterioles (PAs) and right ventricle (RV) without significant immune-mediated damage in experimental pulmonary arterial hypertension (PAH) mice models.

Objective: Here, we aim to further evaluate the long-term effects of ETRQ $\beta-002$.

Methods: $\mathrm{PAH}$ mice model was induced by a combination of subcutaneous injection with Sugen5416 and chronic hypoxic conditions $\left(10 \% \mathrm{O}_{2}\right)$. PAH mice were immunized with ETRQ $\beta-002$ at different time points, and the experiment lasted for 21 weeks. Hemodynamic, histological, and biochemical analyses were conducted to evaluate the long-term effects of ETRQ $\beta-002$.

Results: We demonstrated that the titer of the specific antibody against ETR-002 could be maintained chronically after periodic booster immunization in PAH mice. Long-term reduction of right ventricular systolic pressure and amelioration of PA remodeling by ETRQ $\beta$-002 were confirmed. Moreover, we found that ETRQ $\beta-002$ also exerted antiproliferation, anti-inflammation, and antifibrosis effects in PA remodeling. Besides, ETRQ $\beta-002$ durably limited pathological RV hypertrophy and fibrosis. Finally, no immune-mediated damage was observed in hepatic or renal function or by pathology in liver and kidney during the long-term administration of ETRQ $\beta-002$.

Conclusion: Our findings indicate that ETRQ $\beta-002$ provides long-term therapeutic effects in Sugen/hypoxia-induced PAH animals and offers a promising clinical prospect for PAH treatment.

Keywords: pulmonary arterial hypertension, endothelin-A receptor, vaccine therapy, durable efficacy, vascular remodeling 


\section{INTRODUCTION}

Pulmonary arterial hypertension (PAH) is a chronic lifethreatening disease characterized by pulmonary arteriole (PA) remodeling. Pathological changes of $\mathrm{PA}$ in $\mathrm{PAH}$, including thickening of intimal and medial layers, fibrotic vasculopathy, and perivascular inflammatory cell infiltration (1-3), lead to a progressive elevation of pulmonary arterial pressure and, eventually, right ventricular failure. In recent years, clinical, functional, and hemodynamic improvement in $\mathrm{PAH}$ patients has been achieved with the application of a collection of targeted drugs such as endothelin-receptor antagonists, phosphodiesterase type 5 inhibitors, and prostacyclin derivatives (4). Despite the great advances in pharmacological therapy, the quality of life and prognosis of $\mathrm{PAH}$ patients remain poor, with a 5 -year survival rate of $69 \%$ (5). Thus, it is urgent to explore novel and affordable therapeutic approaches for the treatment of PAH.

Therapeutic vaccine is a new method for treating chronic diseases (6). Unlike preventive vaccines, therapeutic vaccines mainly aim at self-antigens. Self-antigen alone does not always break tolerance and lead to an immune response. To improve the immunogenicity, the self-antigens are conjugated with foreign carriers, such as virus-like particles (VLPs). Through a series of immune responses, self-antigen-carrier conjugate would break through self-immune tolerance and induces a specific antibody, which can bind to the antigen, thereby exerting a therapeutic effect. Meanwhile, the self-epitopes are segregated from Tc (cytotoxic $\mathrm{T}$ cell) due to the structure of the peptide-based vaccine, and there are no self-T-cell epitope-specific T-cell clones to cause autoimmune damage (7). Therefore, vaccines comprising self-antigens coupled to carriers present candidates capable of achieving efficacious antibody levels while fulfilling the necessary safety criteria.

It is now well-known that the abnormal activation of endothelin (ET) system, especially ET-1 and ET(A) receptors, plays a critical role in the pathogenesis of $\mathrm{PAH}$ (8). A series of clinical studies have shown that ET receptor antagonists effectively improve the symptoms and clinical deterioration time of patients with PAH (9). Our previous study has demonstrated that a therapeutic vaccine targeting ETAR (termed ETRQ $\beta$ 002) effectively decreases right ventricular systolic pressure (RVSP) in experimental PAH rodent animals. In addition, ETRQ $\beta$-002 vaccine alleviates pathological remodeling of PAs and right ventricular, while exhibiting a satisfactory safety profile (10). However, in the previous research, the period of observation was relatively short in $\mathrm{PAH}$ animals, rendering it difficult to evaluate the durable efficacy of ETRQ $\beta-002$. Moreover, prophylactic administration of ETRQ $\beta-002$ markedly improved hemodynamics, right ventricle (RV) hypertrophy, and PA remodeling. However, whether therapeutic effect could be provided when ETRQ $\beta-002$ is administered after the establishment of hemodynamic $\mathrm{PH}$ also needs to be investigated.

In this study, a relatively long-lasting experiment was performed in Sugen/hypoxia (SuHx)-induced PAH mice. During the process of $\mathrm{PAH}$ induction, mice were immunized with ETRQ $\beta-002$ at different points of time, aiming to verify if ETRQ $\beta-002$ is capable of exerting long-acting protective effects in well-established PAH mice. Moreover, mounting evidence shows that ET system is implicated in various pathological processes including proliferation (11), inflammation, and fibrosis (12, 13), all of which are vital initiators of PA remodeling in $\mathrm{PAH}$. The main signal pathways involved in these pathological processes in $\mathrm{PAH}$ including mitogen-activated protein kinases (MAPKs) and transforming growth factor $\beta$ (TGF- $\beta$ ) pathways. Nuclear factor $-\kappa \mathrm{B}(\mathrm{NF}-\kappa \mathrm{B})$, which is a transcription factor and plays a critical role in inflammation regulation, is also involved in $\mathrm{PAH}$ pathogenesis $(14,15)$. Based on these facts, we proposed and verified the hypothesis that ETRQ $\beta-002$ may offer potential antiremodeling effects in PA partly through attenuating the above pathological processes.

\section{MATERIALS AND METHODS}

\section{Ethics Statement}

The study was carried out in strict accordance with the Guidelines for the Care and Use of Laboratory Animals (Science \& Technology Department of Hubei Province, PR China, 2005). The protocol was approved by the Ethics Committee of Tongji Medical College of Huazhong University of Science and Technology, China. Mice were housed in a specific pathogen-free laboratory at $22^{\circ} \mathrm{C}$, with a 12 -h light-dark cycle, and provided with sterile water, standard chow diet.

\section{Vaccine Preparation and Experimental PH Model}

ETRQ $\beta-002$ vaccine was prepared as previously described (10). Male C57BL/6 mice (Vital River, Beijing, China) aged 6 weeks were randomly divided into five groups: (1) a control group received only vehicle (Con, $n=14$ ); (2) a hypoxia- and Su5416exposed group (SuHx, $n=26$ ); (3) a SuHx + ETRQ $\beta-002(\mathrm{~s})$ group (simultaneous vaccination and SuHx exposure) $(n=26)$; (4) a SuHx + ETRQ $\beta$-002(e) group (vaccination after established $\mathrm{PAH})(n=26)$; (5) a SuHx + VLP group $(n=26)$. All mice except the control group experienced a weekly injection of Su5416 (20 $\mathrm{mg} / \mathrm{kg}$, TargetMol) and were exposed to chronic normobaric hypoxia in a hypoxic chamber flushed with a mixture of $\mathrm{N}_{2}$ and room air $\left(10 \% \mathrm{O}_{2}\right)$. The mice in the SuHx + ETRQ $\beta-002(\mathrm{~s})$ group were immunized with ETRQ $\beta-002$ vaccine $(100 \mu \mathrm{g}$ per mice) on days $0,14,28,42$, and 77 before exposure to chronic hypoxia, whereas the mice in the SuHx + ETRQ $\beta-002(e)$ group were immunized with ETRQ $\beta-002$ vaccine (100 $\mu$ g per mice) on days $28,42,56,70$, and 105 when the hypoxia-induced PAH has been established. After being exposed to chronic normobaric hypoxia for 3 weeks, the animals were followed by re-exposure to normoxia $\left(21 \% \mathrm{O}_{2}\right)$ for 18 additional weeks. ETRQ $\beta-002$ vaccine-specific peptide antibody titer in groups 3 and 4 was detected by enzyme-linked immunosorbent assay (ELISA) every 2 weeks after the second immunization. All mice were sacrificed on day 148 .

\section{Hemodynamic Measurements}

Mice were anesthetized with ketamine (100 mg/kg). RVSP was measured as previously reported (16) with polyethylene catheters (Scientific Commodities Inc., Lake Havasu City, Arizona) via a 
polygraph system (LabChart 7.3.7; AD Instruments, New South Wales, Australia) using pressure catheters (SPR-671; Millar, Texas, USA).

\section{Morphological Assessment}

Lungs and RV specimens were washed by phosphate-buffered saline and immediately fixed in $10 \%$ formalin and embedded in paraffin as previously described (16). Cardiomyocyte diameters of the RV were determined through wheat germ agglutinins (WGAs). The fibrotic area (\%) of PA and RV was evaluated through Masson trichrome staining. PA remodeling was calculated by hematoxylin-eosin and $\alpha$-smooth muscle actin (anti- $\alpha$-SMA; Sigma). The percentage of medial wall thickness (MT\%) of vessels (20- to $70-\mathrm{mm}$ diameter) was measured, and the degree of muscularization of vessels was categorized as non-muscular, partially muscular or fully muscular, according to the previously described (10). Parts of fresh renal cortex were immediately fixed in $0.25 \%$ glutaraldehyde for transmission electron microscopy (TEM). All of the analyses were performed blinded to the study conditions.

\section{Lung Immunohistochemistry and Immunofluorescence}

Lung sections was performed with immunohistochemical staining (including PCNA and CD68) and immunofluorescence staining (including $\alpha$-SMA, Ki67, CD45, and collagen III) according to the previous method (17). The number of proliferating marker cells and inflammatory cells in vessels and perivascular tissues was counted in a blinded fashion in 15-25 randomly chosen high-powered fields. The $\alpha$-SMA-collagen III colocalization was expressed as percent double-positive area/sum total area of stain for each protein of PAs.

\section{Protein and mRNA Analysis}

RNA isolation, cDNA synthesis, quantitative real-time polymerase chain reaction (qRT-PCR), protein extraction, and Western blotting were performed as previously described (17). qRT-PCR on resulting cDNA were performed to determine relative expression of each gene of interest, determined by the $2^{-\Delta \Delta \mathrm{Cq}}$ method and normalized to the relative expression of $18 \mathrm{~S}$. Sequences of primers are provided in Supplementary Table 1. Densitometric analyses of Western blot results were quantified using Image Lab software (Bio-Rad Laboratories, CA, USA) and were expressed relative to the mean of the control group. All the antibodies used in Western blot are listed in Supplementary Table 2.

\section{Statistical Analysis}

Data were initially screened for normality using the ShapiroWilk test and were expressed as mean \pm standard error of the mean (SEM). A one-way analysis of variance (ANOVA) using Bonferroni's method (for comparison of more than two groups) was used for the statistical analyses. The differences in some observations [MT, cross-sectional area (CSA), PCNA, Ki67, CD45, CD68, fibrosis, and colocalization of Pas] were analyzed using a mixed-effects model. If the assumption of the homogeneity of variances was violated, as assessed with the
Levene test for equality of variances, Welch ANOVA was used with the Games-Howell post hoc test for pairwise comparisons. The calculation was carried out using the statistical program SPSS version 19.0. $P<0.05$ was accepted as significant.

\section{RESULTS}

\section{ETRQ $\beta-002$ Exerted Long-Term Effects of Attenuating PAH and Reducing PA Thickening in SuHx-Induced PAH}

To identify durable efficacy of ETRQ $\beta-002$ and whether therapeutic effect could be exerted in established PAH model, we randomly assigned male C57BL/6 mice into five groups, and the study duration for this $\mathrm{PAH}$ model was $\sim 150$ days (Figure 1A). After four basic immunizations, special antibody in serum of mice immunized with ETRQ $\beta-002$ was detected. ELISA test revealed that antibody titers in the SuHx + ETRQ $\beta-002(s)$ group and the SuHx + ETRQ $\beta-002(\mathrm{e})$ group were 1:1,000,000 to $1: 1,100,000$ and $1: 900,000$ to $1: 1,100,000$, respectively. Five weeks after the fourth immunization, a booster immunization was performed because of the lowered antibody titer. Afterward, the antibody titers increased again and maintained at a high level until sacrifice (Figure 1B).

Further, the long-term protective efficacy was investigated. Hemodynamic result showed that RVSP significantly increased in all the groups treated with SuHx. However, RVSP in the SuHx + ETRQ $\beta$-002(s) and SuHx + ETRQ $\beta$-002(e) groups decreased markedly compared with the SuHx group (ETRQ $\beta-002(\mathrm{~s}), 23.38$ $\pm 0.67 \mathrm{~mm} \mathrm{Hg}, P=0.012$; ETRQ $\beta-002(\mathrm{e}), 23.99 \pm 0.72 \mathrm{~mm}$ $\mathrm{Hg}, P=0.023$; SuHx $30.72 \pm 1.86 \mathrm{~mm} \mathrm{Hg}$; Figures 1C,D). No significant difference was detected between the SuHx + ETRQ $\beta$ 002(s) group and the SuHx + ETRQ $\beta-002(\mathrm{e})$ group. Then, PA pathological remodeling including media wall thickness (MT) and fraction of muscularized arteries were evaluated. As the results shows, the MT\% remarkably increased in all the groups except the control group. However, the MT\% in the SuHx + ETRQ $\beta$-002(s) group and the SuHx + ETRQ $\beta$-002(e) group was significantly lower than that of the SuHx group (ETRQ $\beta$ 002 (s), $0.248 \pm 0.008, P<0.001$; ETRQ $\beta-002(\mathrm{e}), 0.262 \pm 0.008$, $P<0.001$; SuHx $0.329 \pm 0.007$; Figures 1E,F). In addition, ETRQ $\beta-002$ also reversed the partial muscularization of PAs (ETRQ $\beta-002(\mathrm{~s}), 0.390 \pm 0.016, P<0.001$; ETRQ $\beta-002(\mathrm{e}), 0.464$ $\pm 0.023, P=0.015$; SuHx $0.579 \pm 0.032$; Figure 1G). Fraction of fully muscularization increased in mice treated with $\mathrm{SuHx}$ was decreased by ETRQ $\beta-002$ administration, but did not reach statistical significance. These results indicated that given periodic enhancement of immunity, ETRQ $\beta-002$ provides a durable efficacy in established PAH model.

\section{ETRQ $\beta$-002 Ameliorated Proliferation of PA and Inhibited Phosphorylation of ERK1/2 and p38 in SuHx-Induced PAH}

Similar to cancer, $\mathrm{PAH}$ is a proliferative disease characterized by accumulation of diverse vascular cells in the pulmonary arterial wall $(2,14)$. To evaluate the antiproliferative efficacy of ETRQ $\beta-002$, PCNA (proliferating cell nuclear antigen) 


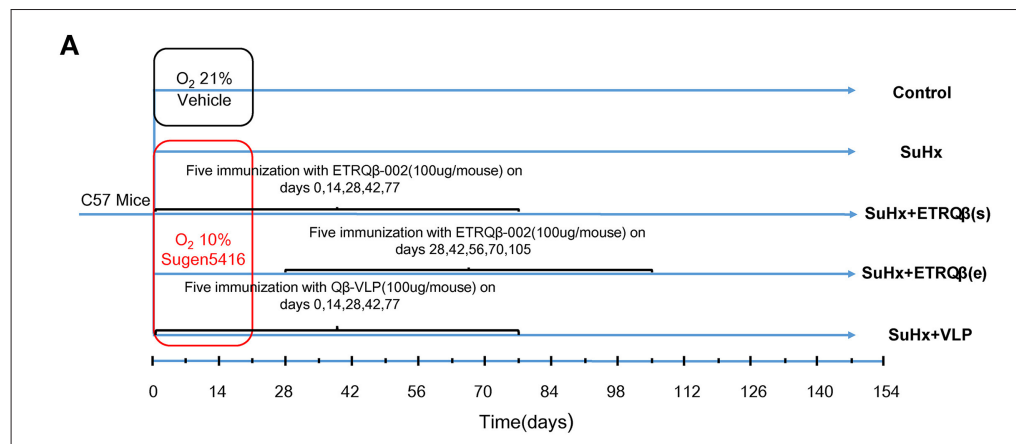

B
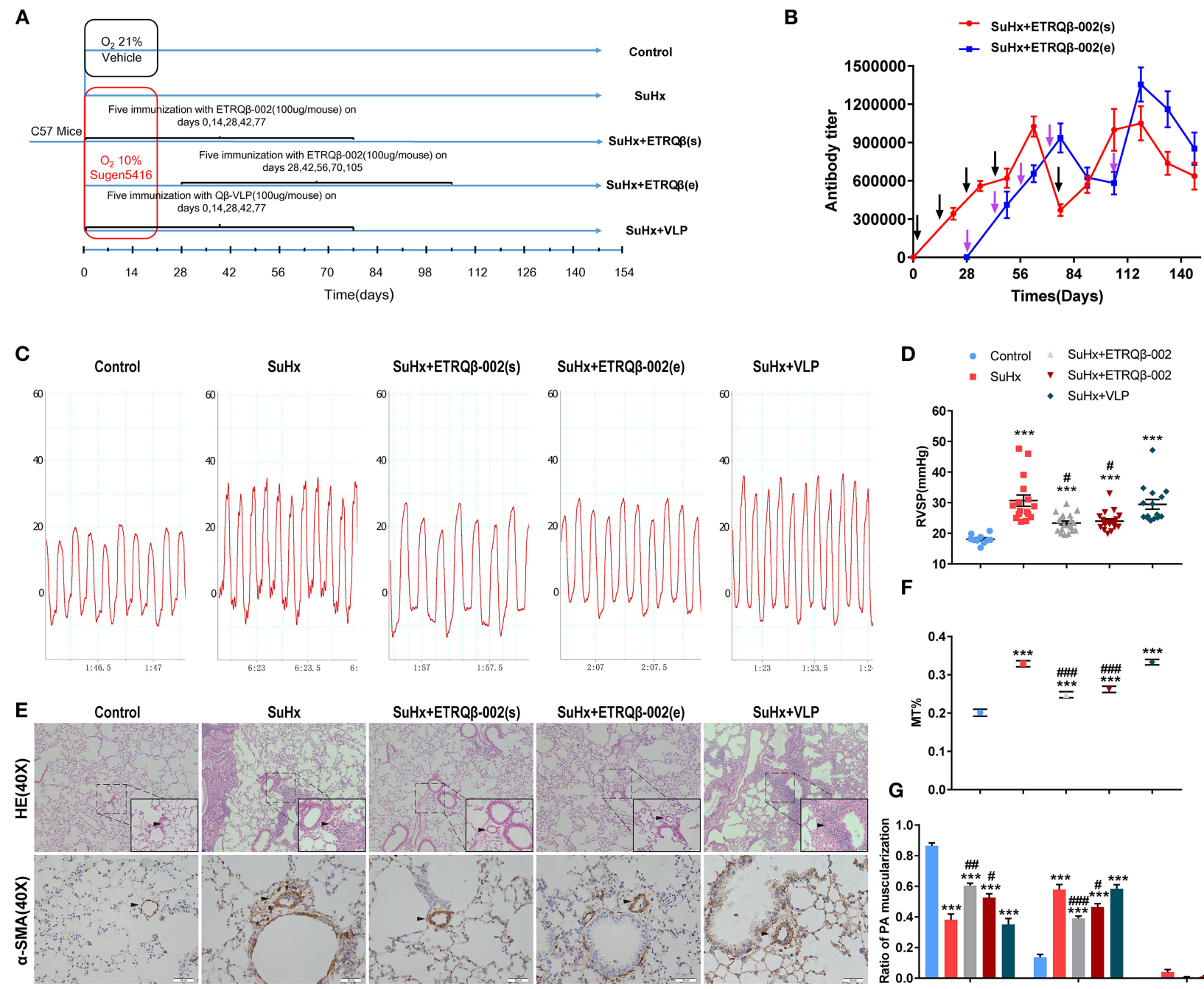

$\mathbf{F}$

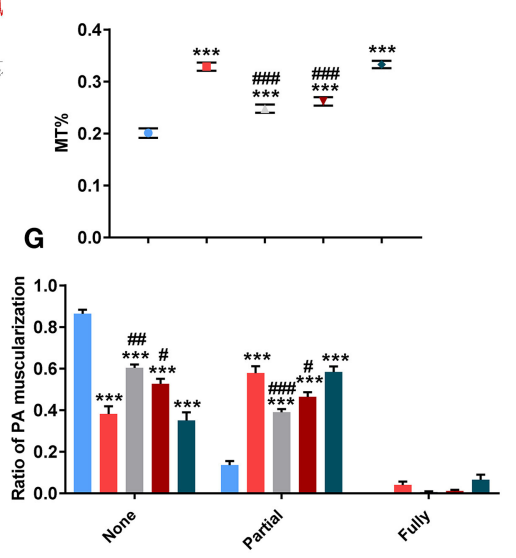

FIGURE 1 | Long-term efficacy of ETRQ $\beta-002$ vaccine in SuHx-induced PAH mice. (A) The progress map of SuHx-induced mice PAH model. (B) The ETRQ $\beta$-002 specific antibody titers were screened on days $21,35,49,63,77,91,105,119,133$, and 147 in the SuHx + ETRQ $\beta$-002(s) group ( $n=10)$, whereas on days 49 , 63, $77,91,105,119,133$, and 147 in the SuHx + ETRQ $\beta-002(e)$ group $(n=10)$. The black and purple arrows refer to the ETRQ $\beta$-002 injections in the SuHx + $E T R Q \beta-002(s)$ group and SuHx + ETRQ $\beta-002(e)$ group, respectively. (C) Representative images of the pulmonary hypertension in the five groups. (D) RVSP measured by right cardiac catheterization on day $148(n=10-19)$. (E) Representative photographs of hematoxylin-eosin (HE) and $\alpha$-smooth muscle actin ( $\alpha$-SMA) staining of lung sections from each group (scale bar $=50 \mu \mathrm{m}$ ). (F) The percentage medial wall thickness (MT\%) of vessels (diameter, 20-70 $\mu \mathrm{m} ; n=8-10)$. (G) Ratio of PA muscularization (none, partial, and fully; $n=8-10$ ). The black arrows refer to the PAs. All data are expressed as the mean \pm SEM. ${ }^{\star \star \star} P<0.001$ vs. the control group; $\# P<0.05, \# \# P<0.01, \# \# \#<0.001$ vs. the SuHx group.

immunohistochemical staining, and Ki67/ $\alpha$-SMA doubleimmunofluorescence staining were performed in lung sections of all the mice. Results demonstrated that $\mathrm{SuHx}$ exposure observably increased the number of PCNA-positive and Ki67positive cells in vessels and perivascular tissues (Figures $2 \mathrm{~A}-\mathbf{D}$ ), but ETRQ $\beta-002$ effectively restrained this change. However, we also found a larger number of proliferating marker cells in the ETRQ $\beta-002$ (e) group than the ETRQ $\beta$-002(s) group.

Mounting evidence shows that aberrant ERK and p38 activation play a potent role in $\mathrm{PAH}$ pathobiology $(18,19)$. Consistent with the antiproliferative effect of ETRQ $\beta-002$ in our previous study in vitro, elevated phosphorylation of ERK1/2 observed in SuHx-exposed lungs was markedly attenuated by ETRQ $\beta-002$ administration (ETRQ $\beta-002(s), 63 \%$ decrease, $P<0.001$; ETRQ $\beta-002(\mathrm{e}), 58 \%$ decrease, $P<0.001$; Figures 2E,F). Similar result was found in phosphorylation of p38 (ETRQ $\beta-002(\mathrm{~s}), 51 \%$ decrease, $P=0.036$; ETRQ $\beta$ 002(e), 31\% decrease, $P=0.332$; Figures 2G,H). Moreover, compared to the SuHx group, increased mRNA expression of growth factors associated with $\mathrm{PAH}$ in lung was also significantly down-regulated in mice immunized with ETRQ $\beta$ 002 (Figure 2I). It is worth noting that phosphorylation level 


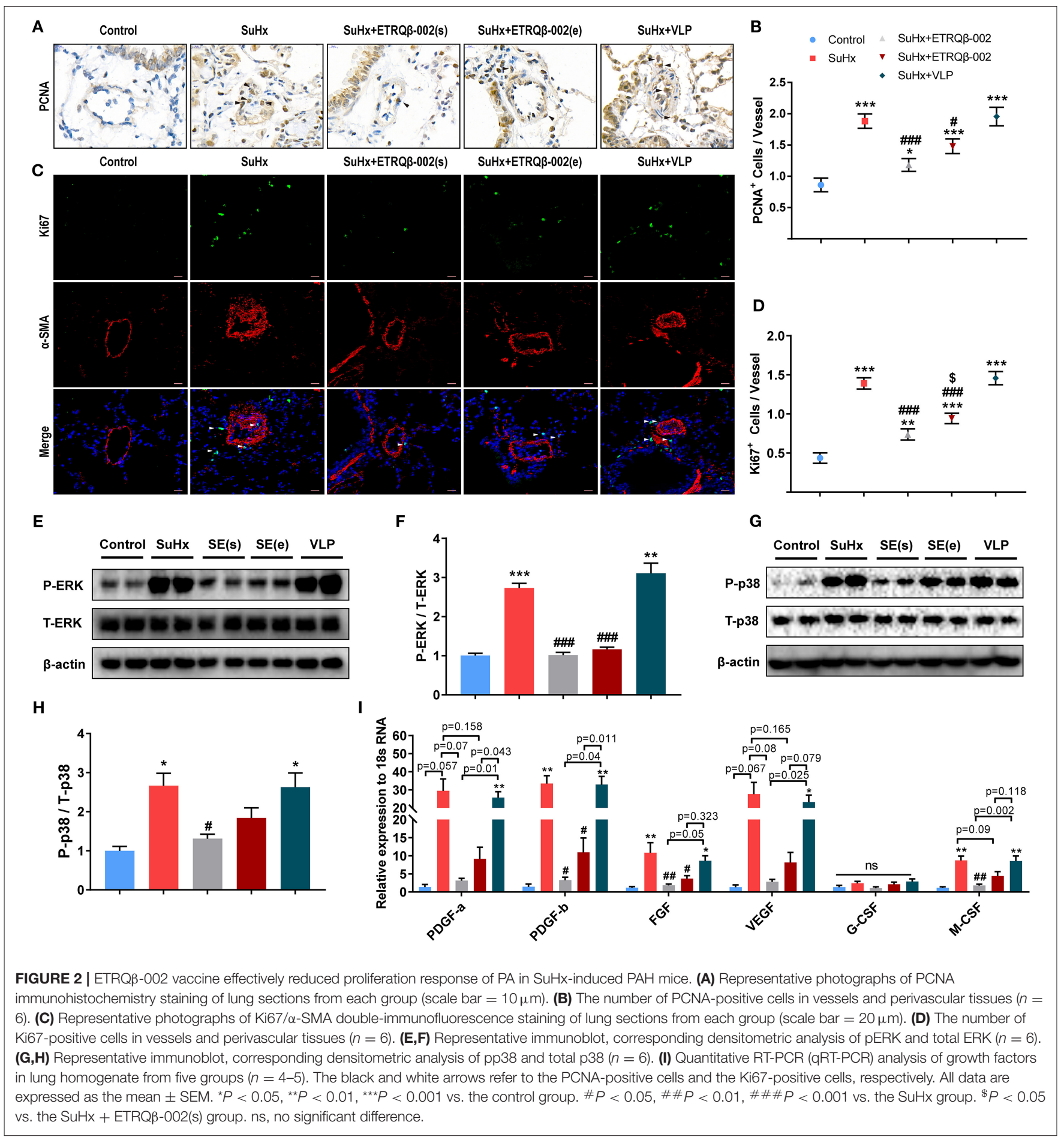

of ERK1/2 and p38 and mRNA expression of growth factors in the ETRQ $\beta-002(e)$ groups are slightly higher than those in the ETRQ $\beta-002(s)$ groups. These results indicated that antiproliferative effects were more superior when mice were immunized with ETRQ $\beta$-002 earlier during the process of $\mathrm{PAH}$ induction.

\section{ETRQ $\beta$-002 Attenuated Inflammation of PA and Inhibited NF- $\kappa$ B Pathway in SuHx-Induced PAH}

In addition to the accumulation of vascular cells, PA remodeling in PAH is also characterized by exaggerated perivascular infiltration of inflammatory cells $(1,2)$. Then, staining and 


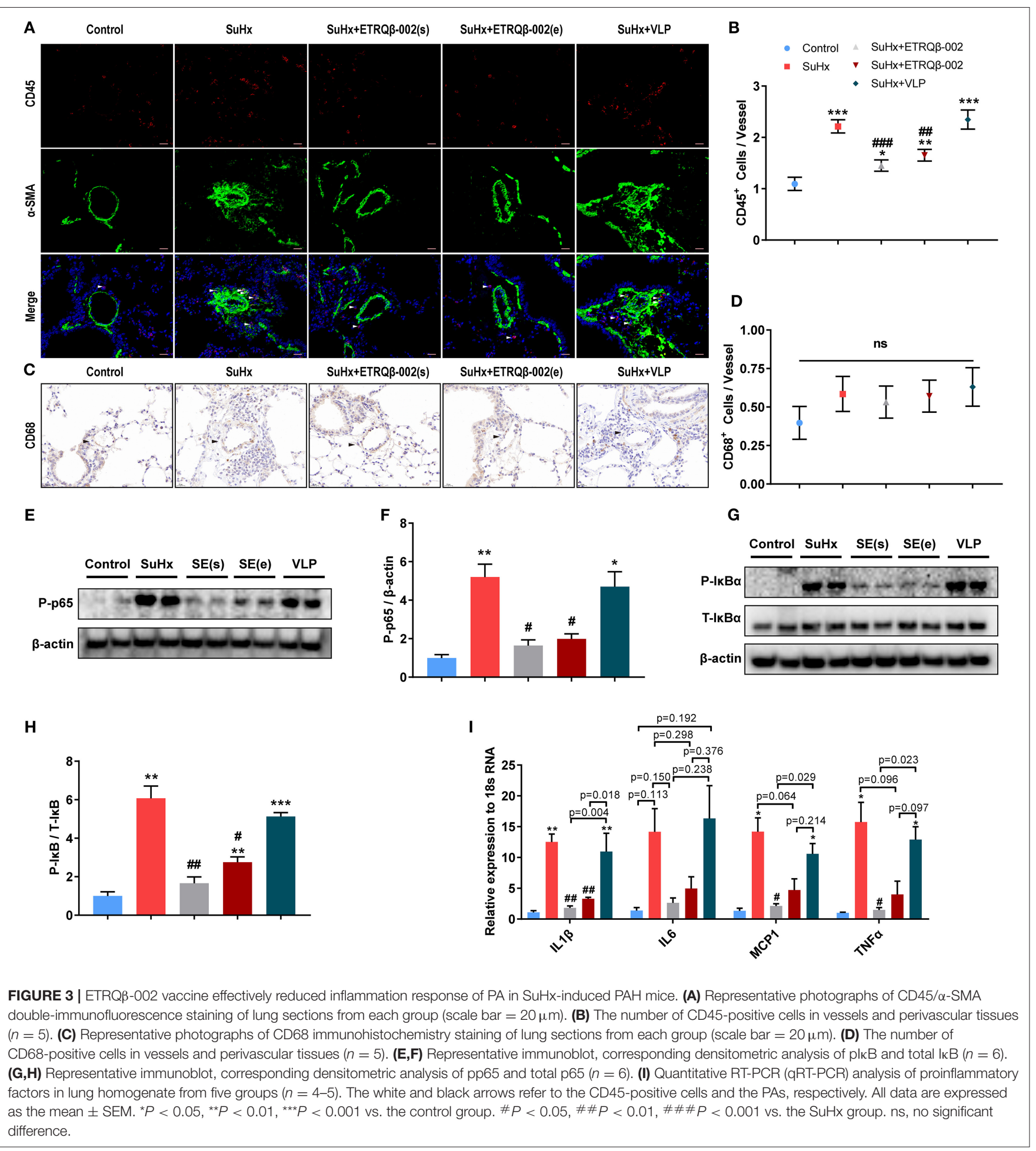

quantification of representative inflammatory and immune cells including macrophages and lymphocytes in lung were carried out. As shown in Figures 3A,B, there was a significant increase of the number of perivascular $\mathrm{CD}_{4} 5^{+}$cells in all $\mathrm{SuHx}-$ exposed lung, but the number of those was significantly lower in the ETRQ $\beta-002(\mathrm{~s})$ and ETRQ $\beta-002(\mathrm{e})$ groups. Our data suggested that ETRQ $\beta$-002 administration decrease perivascular infiltration of lymphocytes cells in PAH. However, no significant difference was observed in number of perivascular $\mathrm{CD}^{+} 8^{+}$cells in all groups (Figures 3C,D).

It is universally acknowledged that, as a leading regulator of inflammation, NF- $\kappa$ B plays a central role in the inflammatory 
response of PAH. Activated NF- $\kappa$ B pathway promotes expression of various genes encoding proinflammatory cytokines and therefore causes vascular inflammation $(15,20,21)$. To determine whether ETRQ $\beta-002$ could inhibit activation of $\mathrm{NF}-\kappa \mathrm{B}$, the protein expression of phosphor-NF- $\kappa \mathrm{B}$ (p-p65), which indicates NF- $\mathrm{B}$ activity, was assessed in lung tissue homogenate. The results demonstrated that ETRQ $\beta-002$ not only decreased phosphorylation of NF-кB induced by SuHx, but also reduced phosphorylation of the cytoplasmic inhibitor IкB (Figures 3E-H), which is a key event in activation of the NF-кB pathway (22). Next, mRNA expression of inflammatory cytokines of lungs in all the groups were measured by qRT-PCR. As shown in Figure 3I, ETRQ $\beta-002$ treatment effectively reduced mRNA expression of classical proinflammatory cytokines including

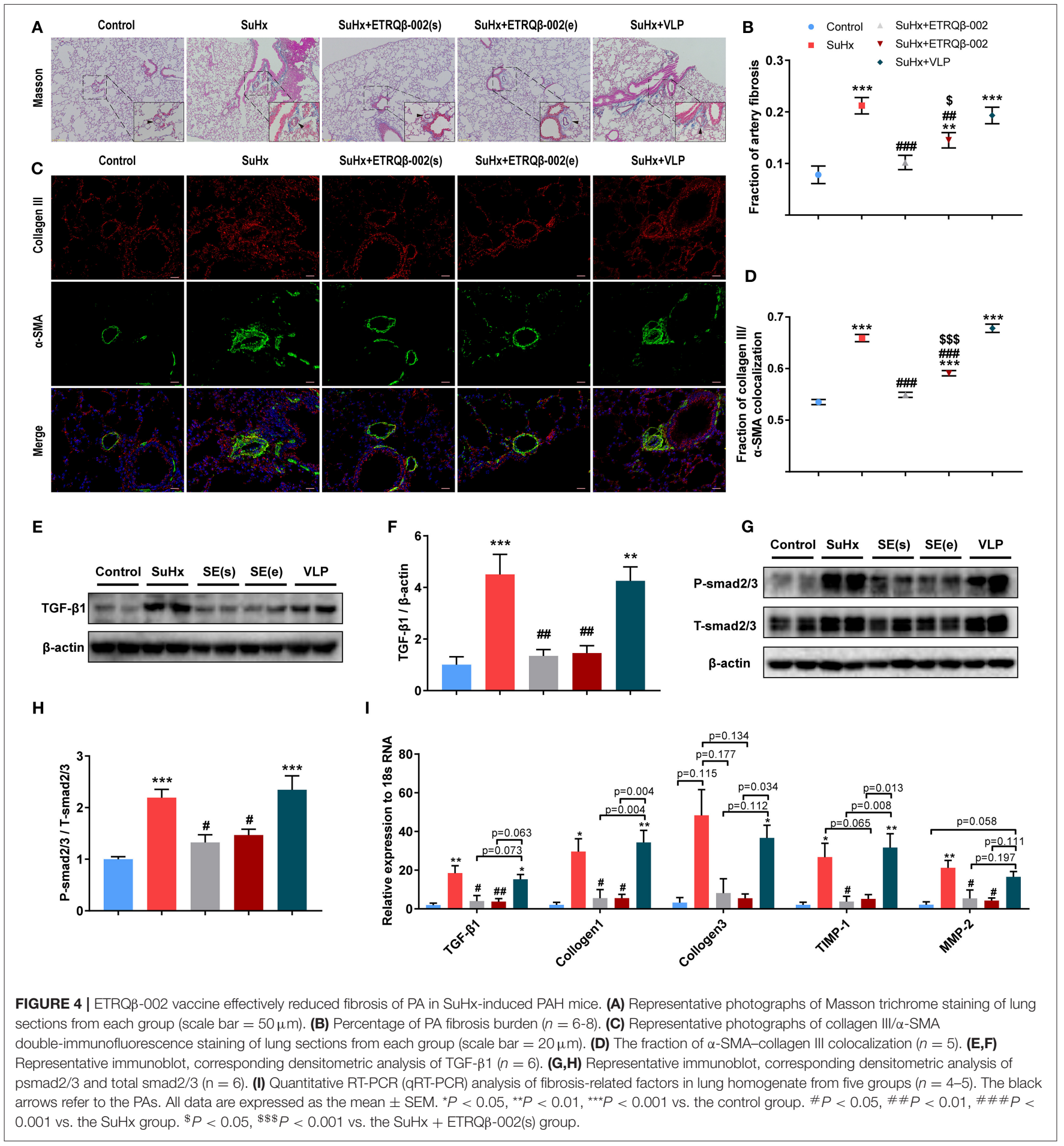


IL-1 $\beta$, IL-6, monocyte chemoattractant protein 1, and tumor necrosis factor $\alpha$, some of which were significantly increased in patients with $\mathrm{PAH}(23,24)$.

\section{ETRQ $\beta-002$ Attenuated Collagen Synthesis of PA and Inhibited Fibrosis Pathway in SuHx-Induced PAH}

Aberrant accumulation of collagen and fibronectin in PA cause vessel stiffness, which is a crucial characteristic of vascular remodeling in PAH $(25,26)$. As shown in Figures $4 \mathbf{A}, \mathbf{B}$, Masson trichrome staining of the lung revealed that, compared to the control group, SuHx-induced $\mathrm{PAH}$ mice revealed a markedly higher percentage of collagen fibers in PA, which was significantly attenuated by ETRQ $\beta-002$ treatment. Further, immunofluorescence showed that ETRQ $\beta-002$ administration decreased the augmentation of $\alpha$-SMA, collagen III, and $\alpha$ SMA-collagen III colocalization in PA from SuHx-PAH mice (Figures 4C,D).

The TGF- $\beta 1 / \mathrm{Smad} 2 / \mathrm{Smad} 3$ pathway plays an important role in cardiovascular fibrosis, and imbalance between TGF- $\beta$ signaling and BMPRII signaling have been proven to contribute to $\mathrm{PAH}$ pathogenesis $(27,28)$. Western blotting showed that the expression of TGF- $\beta 1$ and phosphorylation of $\operatorname{smad} 2 / 3$ in lung tissue homogenate were both decreased by ETRQ $\beta$ 002 treatment (Figures 4E-H). Next, we examined mRNA expression of fibrosis-related factors in lung tissues in all the groups. Consistent with previous results, TGF- $\beta 1$, collagen I, and collagen III were upregulated in SuHx-induced PAH mice, but all of those were downregulated in the ETRQ $\beta$-002 treatment groups (Figure 4I). Besides, ETRQ $\beta$-002 lowered mRNA expression of TIMP-1 and MMP-2 (Figure 4I), which are closely associated with extracellular matrix remodeling of PA and display increased production and activity in patients with IPAH and hypoxiainduced experimental PAH models (29). In general, these data support the conclusion that the ETRQ $\beta-002$ reduces collagen synthesis and fibrosis in PA through inhibiting the TGF$\beta 1 / \mathrm{Smad} 2 / 3$ pathway.

\section{ETRQ $\beta-002$ Attenuated Right Ventricular Hypertrophy and Myocardial Fibrosis in SuHx-Induced PAH}

Longevity in patients with $\mathrm{PAH}$ is strongly determined by right ventricular function (30). Hence, RV compensatory remodeling, including cardiomyocyte hypertrophy and collagen synthesis, was investigated. As shown in Figures 5A,D, the weight ratio of $\mathrm{RV} /(\mathrm{LV}+\mathrm{S})$ in the SuHx group was higher than the ETRQ $\beta$ 002(s) group and ETRQ $\beta-002(\mathrm{e})$ group (ETRQ $\beta-002(\mathrm{~s}), 0.270$ $\pm 0.005, P<0.001$; ETRQ $\beta-002(\mathrm{e}), 0.280 \pm 0.007, P=0.006$; SuHx $0.314 \pm 0.007)$. And, compared with those in the control group, cardiomyocytes in all groups treated with $\mathrm{SuHx}$ were obviously hypertrophied. The WGA staining revealed the CSA of RV myocardium in the ETRQ $\beta-002(s)$ group and ETRQ $\beta$ 002(e) group was significantly decreased compared to the SuHx group (ETRQ $\beta-002(s), 205.5 \pm 3.37 \mu \mathrm{m}^{2}, P<0.001$; ETRQ $\beta$ 002(e), $217.6 \pm 3.51 \mu^{2}, P<0.001$; SuHx $254.9 \pm 3.31 \mu \mathrm{m}^{2}$, Figures 5B,E). Besides, difference was observed between the
ETRQ $\beta$-002(s) group and ETRQ $\beta-002(\mathrm{e})$ group (ETRQ $\beta-002(\mathrm{~s})$ vs. ETRQ $\beta-002(e), P=0.013)$. Moreover, Masson trichrome staining of RV showed that ETRQ $\beta$-002 remarkably decreased the fibrosis induced by SuHx exposure (Figures 5C,F). In the SuHx group, the fibrotic area of RV was $4.55 \pm 0.35 \%$, whereas it was only $2.82 \pm 0.27 \%$ in the ETRQ $\beta-002(s)$ group $(P=0.009)$, and $3.01 \pm 0.22 \%$ in the ETRQ $\beta-002(\mathrm{e})$ group $(P=0.015)$.

Further, right ventricular gene expression affected by pressure overload was also assessed. qRT-PCR analysis showed that ETRQ $\beta$-002 effectively down-regulated the mRNA expression of brain natriuretic peptide (BNP) and $\beta$-MHC in RV tissues from SuHx-exposed mice, but the mRNA expression of $\alpha$-MHC revealed no difference in all groups (Figure 5G). Compared with the SuHx group, the mRNA expression of ratio of $\beta-\mathrm{MHC} / \alpha-$ MHC trended to be decreased in mice immunized with ETRQ $\beta$ 002, but did not reach statistical significance (Figure 5G).

\section{No Safety Problems Were Observed in Vaccinated Mice}

Safety endpoint of ETRQ $\beta-002$ is another concern. To evaluate long-term safety, we compared survival rates in all groups. As shown in Supplementary Figure 1, the survival rate had no obvious difference among groups except for the control group. Moreover, there were no significant differences in hemodynamic parameters including heart rate and systolic blood pressure measured by tail-cuff method in all groups (Supplementary Table 3 ). In addition, after multiple immunizations, biochemical analysis (including hepatic and renal function) did not reveal obvious abnormity in mice treated with ETRQ $\beta-002$ or VLP (Figures 6A,B). Moreover, histological results from important target organs (liver, spleen, and kidney) showed that no significant immune damage was detected in experimental mice (Figure 6C). TEM also showed no obvious injury or immune complex deposition in kidney of vaccinated mice (Figure 6D). These data are in accordance with our previous safety tests and further confirmed that ETRQ $\beta-002$ still displays a good safety during a long period of observation.

\section{DISCUSSION}

Current agents for PAH are required to be taken at least once or sometimes twice a day for many years, which appears to be a major challenge for patient compliance to their treatment. As a new approach for chronic diseases, therapeutic vaccine possesses some special advantages, including high specificity, durable effectiveness, and low cost (6). Previously, based on the structure and rationale of therapeutic vaccine, the peptide derived from the human ETAR was screened and covalently conjugated with VLP, which contains high repetitive epitopes presented on the surface and is effortless to bind to B cells through B cell receptor (BCRs). Then, self-antigen-carrier conjugate (ETRQ $\beta$-002 vaccine) could stimulate B cells to produce specific antibodies targeting ETAR. We demonstrated that ETRQ $\beta-002$ was able to moderate RV pressure elevation, PA remodeling, and RV hypertrophy in two types of PAH rodent models. Here, we confirmed the long-lasting protective effects of ETRQ $\beta-002$ in SuHx-induced PAH mice. 


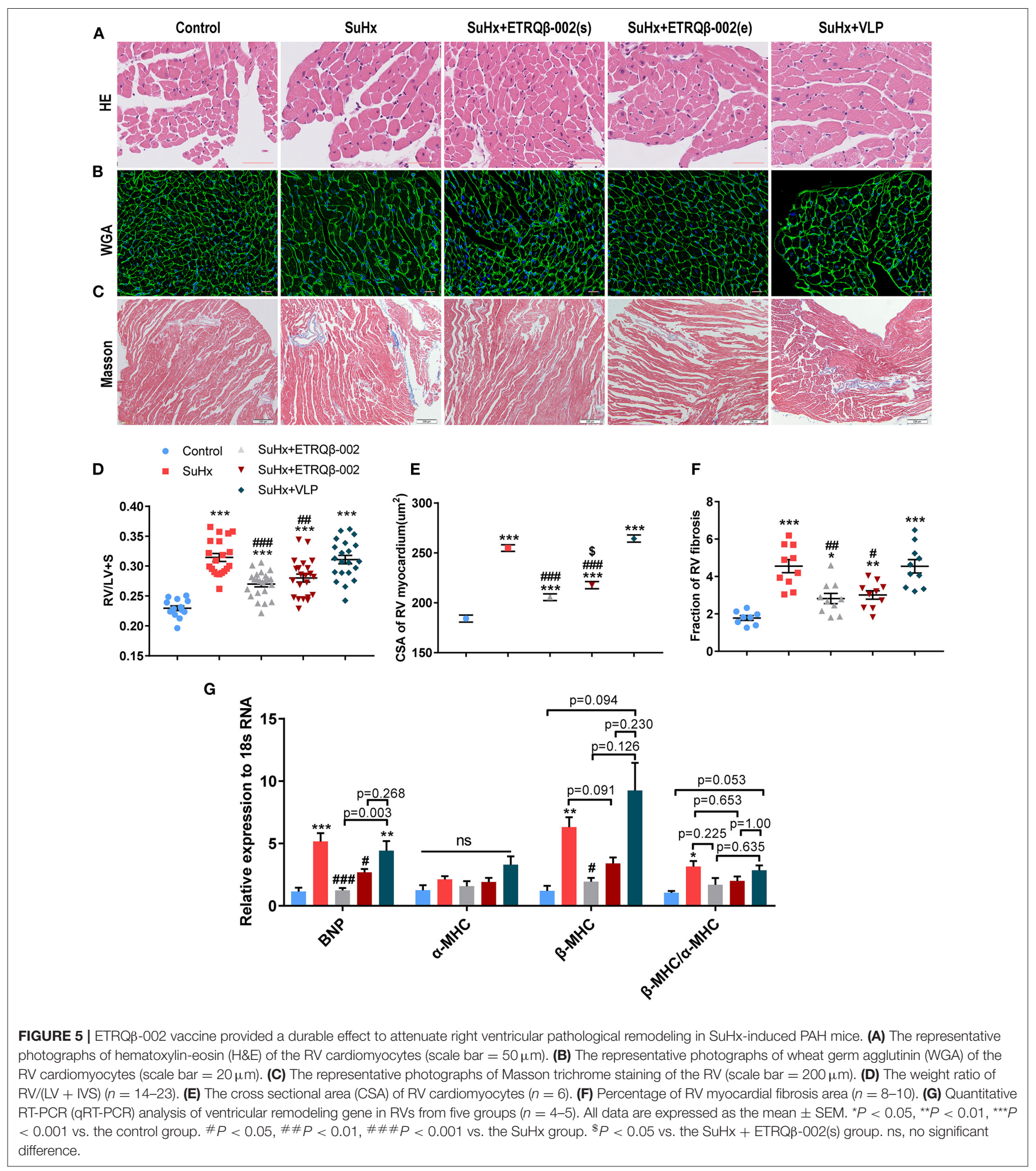

Meanwhile, antiproliferation, anti-inflammatory, and antifibrosis effects in PAs were also observed in PAH mice vaccinated with ETRQ $\beta-002$.

In order to investigate the long-term therapeutic effects of ETRQ $\beta-002$ during the establishment of $\mathrm{PH}$, mice were administered SuHx and vaccine simultaneously in the SuHx + ETRQ $\beta-002$ (s) group. Meanwhile, to examine the effects of the vaccine in well-established $\mathrm{PH}$, mice in the SuHx + ETRQ $\beta$ 002(e) group were vaccinated after SuHx treatment finished. Results showed that the ETRQ $\beta$-002 induced high-level antibody 
A

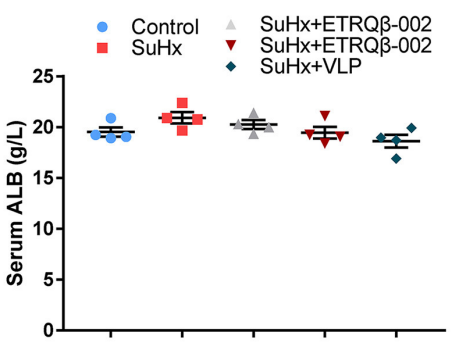

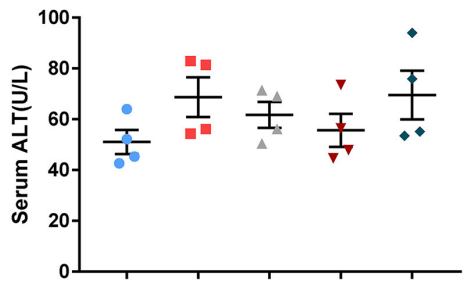

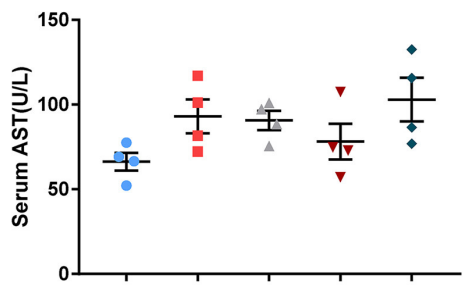

B
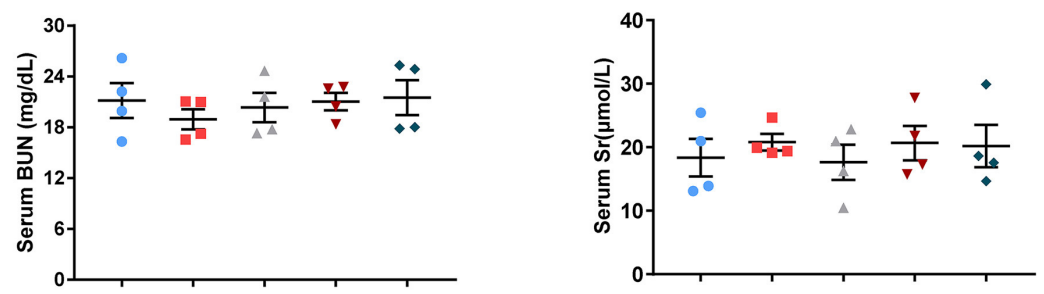

C
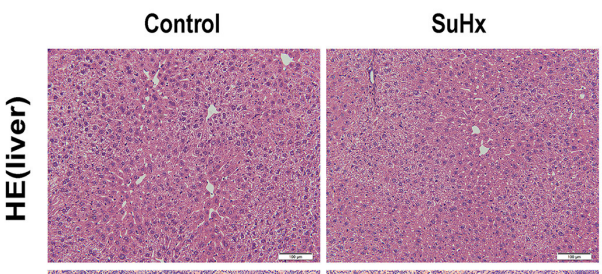

SuHx+ETRQß-002(s)

SuHx+ETRQß-002(e)

SuHx+VLP
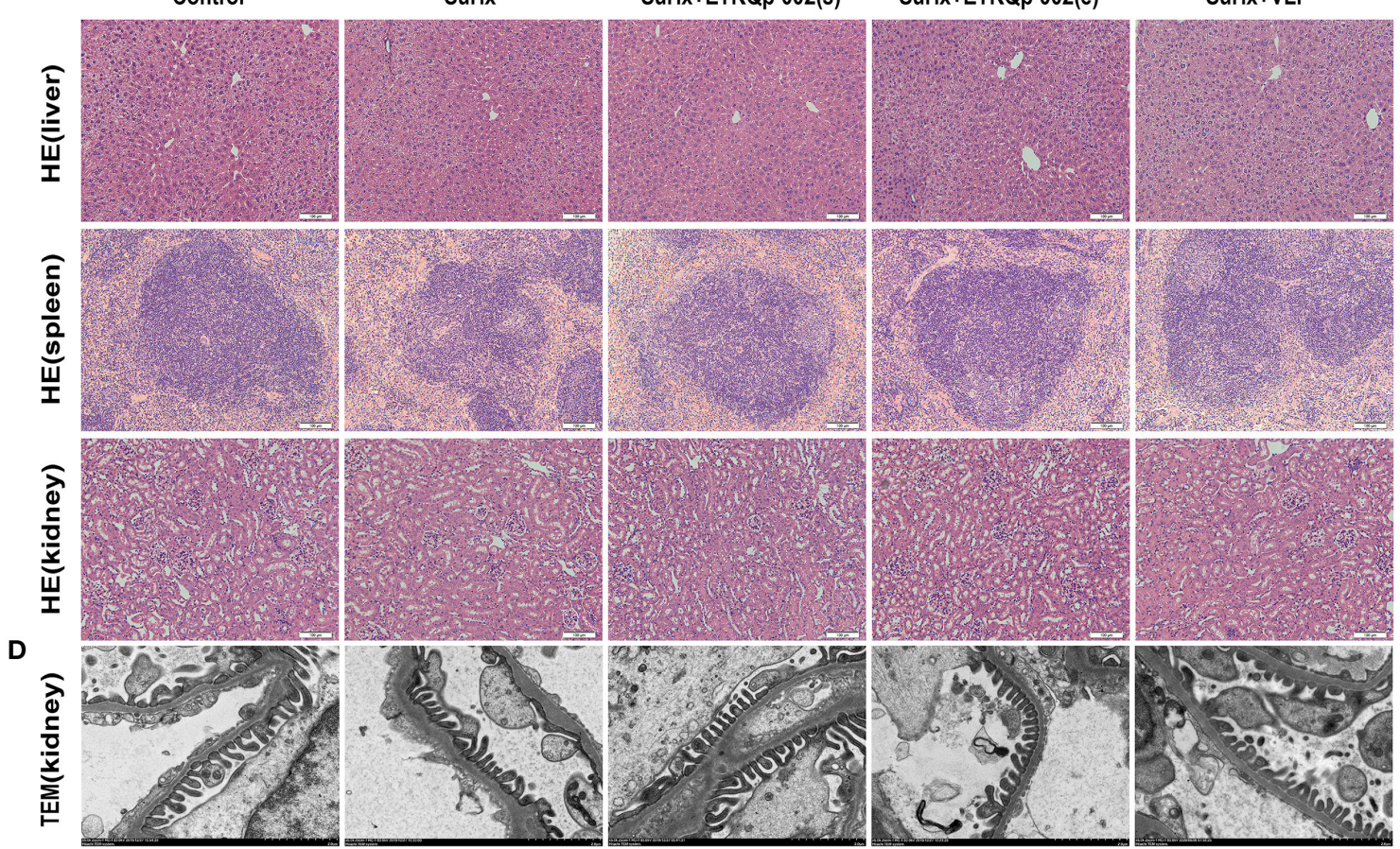

FIGURE 6 | No immune-mediated injury was observed in mice injected with ETRQ $\beta$-002 vaccine during a long-term observation. (A) The hepatic function (ALT, AST, and ALB, $n=4$ ). (B) The renal function [serum creatinine (Scr) and blood urea nitrogen (BUN), $n=4$ ]. (C) The representative photographs of hematoxylin-eosin (HE) of the critical organs (liver, spleen, kidney) in the five groups (scale bar $=100 \mu \mathrm{m}$ ). (D) Transmission electron microscope image of kidney from the five groups (scale bar $=2 \mu \mathrm{m})$. All data are expressed as the mean \pm SEM.

titers, significantly reduced RVSP by about $7 \mathrm{~mm} \mathrm{Hg}$, and improved pathological remodeling of PAs in SuHx mice.

It is well-described that continuous proliferation of pulmonary arterial smooth muscle cells is the crucial pathological characteristics of PAH, leading to medial hypertrophy and progressive occlusion of distal pulmonary resistant vessels (14). ET-1 initiates a series of signal cascades, such as MAPK, Akt, and $\beta$-catenin, and activated MAPK signaling which exhibits a strong proliferative effect in cancer has also been implicated in $\mathrm{PAH}$ $(14,18,31)$. Our previous data demonstrated that anti-ETR-002 antibody inhibited ET-1-induced ERK1/2 phosphorylation in vitro. Here, we further confirmed the antiproliferation effect of ETRQ $\beta-002$ in vivo. Histological and biochemical analyses showed that ETRQ $\beta-002$ effectively reduced PA thickening and numbers of proliferating marker cells in vessels and perivascular tissues. Phosphorylation of ERK1/2 and p38, as well 
as PAH-related growth factors, was also down-regulated in lung of SuHx-induced PAH mice vaccinated with ETRQ $\beta-002$. These results suggested that ETRQ $\beta-002$ displayed a considerable antiproliferation potency in experimental $\mathrm{PAH}$, similar to the effect of endothelin-receptor antagonists in preclinical experimental cancer models (12).

Recent researches have shown the critical role of inflammation in pulmonary vascular remodeling (23). Infiltration of inflammatory cells and proinflammatory cytokines cause excessive proliferation of pulmonary artery endothelial cells and smooth muscle cells. In PAH patients, it has been observed that the numbers of inflammatory cells and levels of proinflammatory cytokines are elevated $(23,24)$. NF- $\kappa \mathrm{B}$ is a major regulator in immunity and inflammatory responses, which could be activated by ET-1 in arterial myocytes (32). Recently, the critical roles of NF- $\mathrm{BB}$ in the pathophysiology of $\mathrm{PAH}$ have been reported, and inhibition of $\mathrm{NF}-\kappa \mathrm{B}$ alleviated inflammation in MCT-PAH animals $(23,33)$. Our data indicated that ETRQ $\beta-002$ significantly reduced lymphocytes cell infiltration in pulmonary artery and its periphery. Additionally, activity of NF- $\kappa \mathrm{B}$ signal path, as well as the mRNA expression of inflammatory factors in SuHx-induced PAH, was also reduced. These results implied that ETRQ $\beta-002$ is able to suppress the inflammatory response and improve $\mathrm{PA}$ remodeling in experimental $\mathrm{PAH}$.

Increased depositions of collagen and elastin are known to be important determinants of medial thickening during the progression of $\mathrm{PAH}$, and pulmonary vascular remodeling is characterized, somewhat, by a fibrotic vasculopathy in small PAs in PAH $(3,34)$. A few studies have revealed that stiffening and decreased compliance in pulmonary vasculature occur in the early stage of $\mathrm{PAH}$, even before the increase of pulmonary arterial pressure $(35,36)$, and thus could better reflect the prognosis of PAH than $\operatorname{PVR}(37,38)$. ET-1 is fundamental to the pathogenesis of fibrosis and may be a pivotal intermediary of profibrotic effects of other mediators. Endothelin-receptor antagonists have been applied to various fibrosis-related diseases including idiopathic pulmonary fibrosis and chronic kidney disease (12); hence, we speculated ETRQ $\beta$ 002 may also have an antifibrosis effect. Here, we found that ETRQ $\beta-002$ did ameliorate collagen deposition in PA, blocked classical fibrosis signaling pathway, as well as reduced the mRNA expression of fibrosis-related factors in SuHxinduced PAH.

The prognosis of patients with $\mathrm{PH}$ is largely determined by the structure and function of RV. Initially, the RV adapts to the increased pressure overload by compensatory processes, including cardiomyocyte hypertrophy, elevated capillary density, and synthesis of extracellular matrix proteins. Finally, as contractile weakening progresses, decompensated right ventricular failure characterized by contractile dysfunction, extensive fibrosis, chamber dilatation, and capillary rarefaction occurs, leading eventually to death $(17,30)$. In our study, significant RV pathological remodeling, including hypertrophy and fibrosis, and up-regulated mRNA expression of ventricular wall stress proteins BNP and adult and fetal isoforms of myosin heavy chain $\beta$-MHC were found in SuHx-induced
PAH mice. ETRQ $\beta$-002 significantly attenuated these changes. Besides, we found that the therapeutic efficacy of ETRQ $\beta$ 002 in experimental PAH might be associated with the time of administration, because data showed that protective effects of the vaccine in the SuHx + ETRQ $\beta-002(s)$ group were better than that in the SuHx $+\operatorname{ETRQ} \beta-002(\mathrm{e})$ group in some aspects, including the proliferation of PA (Ki67), fibrosis of PA, and CSA of RV. These results suggest that earlier vaccination with ETRQ $\beta-002$ might provide better protection.

The long-term safety examination of the vaccine has also been conducted in this study. Although the vaccine did not significantly improve the long-term survival rate of $\mathrm{SuHx}-\mathrm{PAH}$ mice, the obvious side effect was not observed. As the results revealed, multiple ETRQ $\beta-002$ immunizations caused no injury in hepatic and renal function and did not lead to immune damage in important organs of mice. Further, TEM showed that no immune-mediated damage was observed in the kidney of mice immunized with ETRQ $\beta-002$. In principle, the safety of the ETRQ $\beta-002$ vaccine mainly includes the safety of the ETR-002 peptide and Q $\beta$ VLP carrier separately. First, as the ETR-002 peptide is only 10 amino acids in length, which alone does not include a T-cell epitope, it is not able to induce a $\mathrm{T}$-cell response. Thus, Tc will not be activated and does not produce an overall antiendothelial response, just a specific antiETAR from B cells. Second, our previous work found that the peptide-VLP vaccine strongly activated dendritic cells, which promoted $\mathrm{T}$-cell differentiation to follicular helper $\mathrm{T}$ cells instead of Tc or inflammation-related $\mathrm{T}_{\mathrm{H}} 1 / \mathrm{T}_{\mathrm{H}} 2 / \mathrm{T}_{\mathrm{H}} 17$, which showed the good safety of the peptide-VLP vaccine (39). Moreover, several preclinical and clinical trials have shown a good safety of peptideVLP vaccines (40-42). All of these pieces of evidence indicate a long-term safety endpoint of ETRQ $\beta$-002.

Our study has some limitations. First, we used only one model (SuHx mice model), which has a few disadvantages including vascular remodeling and partial recovery of RVSP after exposure to normoxia. However, the RVSP of SuHx mice (hypoxia combined SU5416 injection) will not fully recover even after a long-term normoxic recovery compared with the VehHx mice (hypoxia alone) (43). Moreover, the results in this study showed that ETRQ $\beta-002$ decreased the RVSP (approximately $7 \mathrm{~mm} \mathrm{Hg}$ ) and improved the remodeling of PAs compared with the SuHx group; thus, the long-term effects of the ETRQ $\beta-002$ could be confirmed. Second, although the safety of the ETRQ $\beta-002$ has been initially verified, a more precise long-term safety endpoint of the vaccine needs to be further investigated.

\section{CONCLUSION}

In summary, our study demonstrated that ETRQ $\beta$-002 offers a long-term efficacy in reducing RV pressure and RV remodeling. The vaccine also attenuates crucial pathological process in PAs in SuHx-induced $\mathrm{PAH}$, including proliferation, inflammation, and fibrosis. 


\section{DATA AVAILABILITY STATEMENT}

The original contributions presented in the study are included in the article/Supplementary Material, further inquiries can be directed to the corresponding author/s.

\section{ETHICS STATEMENT}

The animal study was reviewed and approved by Ethics Committee of Tongji Medical College of Huazhong University of Science and Technology, China.

\section{AUTHOR CONTRIBUTIONS}

$\mathrm{YD}, \mathrm{ZQ}$, and WM designed the study. YD and ML wrote the paper. CL, XC, and XS performed the research. ZB, DS, JZ, and

\section{REFERENCES}

1. Savai R, Pullamsetti SS, Kolbe J, Bieniek E, Voswinckel R, Fink L, et al. Immune and inflammatory cell involvement in the pathology of idiopathic pulmonary arterial hypertension. Am J Respir Crit Care Med. (2012) 186:897908. doi: 10.1164/rccm.201202-0335OC

2. Humbert M, Guignabert C, Bonnet S, Dorfmüller P, Klinger JR, Nicolls MR, et al. Pathology and pathobiology of pulmonary hypertension: state of the art and research perspectives. Eur Respir J. (2019) 53:1801887. doi: 10.1183/13993003.01887-2018

3. Maron BA, Galie N. Diagnosis, treatment, and clinical management of pulmonary arterial hypertension in the contemporary era: a review. JAMA Cardiol. (2016) 1:1056-65. doi: 10.1001/jamacardio.2016.4471

4. Montani D, Chaumais MC, Guignabert C, Günther S, Girerd B, Jaïs X, et al. Targeted therapies in pulmonary arterial hypertension. Pharmacol Ther. (2014) 141:172-91. doi: 10.1016/j.pharmthera.2013.10.002

5. Farber HW, Miller DP, Poms AD, Badesch DB, Frost AE, Muros-Le Rouzic E, et al. Five-year outcomes of patients enrolled in the REVEAL Registry. Chest. (2015) 148:1043-54. doi: 10.1378/chest.15-0300

6. Bachmann MF, Dyer MR. Therapeutic vaccination for chronic diseases: a new class of drugs in sight. Nat Rev Drug Discov. (2004) 3:81-8. doi: $10.1038 / \mathrm{nrd} 1284$

7. Zhu F, Zhou Z, Liao Y. The renin-angiotensin system and therapeutic vaccines for hypertension. Curr Opin Investig Drugs. (2008) 9:286-94. doi: 10.2174/157015908783769662

8. Galie N, Manes A, Branzi A. The endothelin system in pulmonary arterial hypertension. Cardiovasc Res. (2004) 61:227-37. doi: 10.1016/j.cardiores.2003.11.026

9. Davenport AP, Hyndman KA, Dhaun N, Southan C, Kohan DE, Pollock JS, et al. Endothelin Pharmacol Rev. (2016) 68:357-418. doi: $10.1124 / \mathrm{pr} .115 .011833$

10. Dai Y, Chen X, Song X, Chen X, Ma W, Lin J, et al. Immunotherapy of Endothelin-1 Receptor Type A for pulmonary arterial hypertension. J Am Coll Cardiol. (2019) 73:2567-80. doi: 10.1016/j.jacc.2019.02.067

11. Peduto Eberl L, Bovey R, Juillerat-Jeanneret L. Endothelin-receptor antagonists are proapoptotic and antiproliferative in human colon cancer cells. Br J Cancer. (2003) 88:788-95. doi: 10.1038/sj.bjc.6600810

12. Aubert JD, Juillerat-Jeanneret L. Endothelin-receptor antagonists beyond pulmonary arterial hypertension: cancer and fibrosis. J Med Chem. (2016) 59:8168-88. doi: 10.1021/acs.jmedchem.5b01781

13. Dhaun N, Webb DJ. Endothelins in cardiovascular biology and therapeutics. Nat Rev Cardiol. (2019) 16:491-502. doi: 10.1038/s41569-0190176-3

14. Pullamsetti SS, Savai R, Seeger W, Goncharova EA. Translational advances in the field of pulmonary hypertension. from cancer biology to new pulmonary arterial hypertension therapeutics. Targeting cell growth and
GP analyzed data. YL, ZQ, and ZZ supervised the research and obtained resources and fundings. All authors contributed to the article and approved the submitted version.

\section{FUNDING}

This work was supported by the National Natural Science Foundation of China (Grant numbers: 82070522, 81974055, and 81770366).

\section{SUPPLEMENTARY MATERIAL}

The Supplementary Material for this article can be found online at: https://www.frontiersin.org/articles/10.3389/fcvm. 2021.683436/full\#supplementary-material proliferation signaling hubs. Am J Respir Crit Care Med. (2017) 195:425-37. doi: 10.1164/rccm.201606-1226PP

15. Farkas D, Alhussaini AA, Kraskauskas D, Kraskauskiene V, Cool CD, Nicolls $\mathrm{MR}$, et al. Nuclear factor kappaB inhibition reduces lung vascular lumen obliteration in severe pulmonary hypertension in rats. Am J Respir Cell Mol Biol. (2014) 51:413-25. doi: 10.1165/rcmb.2013-0355OC

16. Ciuclan L, Bonneau O, Hussey M, Duggan N, Holmes AM, Good R, et al. A novel murine model of severe pulmonary arterial hypertension. Am J Respir Crit Care Med. (2011) 184:1171-82. doi: 10.1164/rccm.201103-0412OC

17. Veith C, Neghabian D, Luitel H, Wilhelm J, Egemnazarov B, Muntanjohl C, et al. FHL-1 is not involved in pressure overload-induced maladaptive right ventricular remodeling and dysfunction. Basic Res Cardiol. (2020) 115:17. doi: 10.1007/s00395-019-0767-5

18. Lane KB, Blackwell TR, Runo J, Wheeler L, Phillips JA, Loyd JE. Aberrant signal transduction in pulmonary hypertension. Chest. (2005) 128(6 Suppl):564S-65S. doi: 10.1378/chest.128.6_suppl.564S-a

19. Wu J, Thabet SR, Kirabo A, Trott DW, Saleh MA, Xiao L, et al. Inflammation and mechanical stretch promote aortic stiffening in hypertension through activation of p38 mitogen-activated protein kinase. Circ Res. (2014) 114:61625. doi: 10.1161/CIRCRESAHA.114.302157

20. Kurosawa R, Satoh K, Kikuchi N, Kikuchi H, Saigusa D, Al-Mamun $\mathrm{ME}$, et al. Identification of celastramycin as a novel therapeutic agent for pulmonary arterial hypertension. Circ Res. (2019) 125:309-27. doi: 10.1161/CIRCRESAHA.119.315229

21. Li L, Wei C, Kim IK, Janssen-Heininger Y, Gupta S. Inhibition of nuclear factor-kappaB in the lungs prevents monocrotaline-induced pulmonary hypertension in mice. Hypertension. (2014) 63:1260-9. doi: 10.1161/HYPERTENSIONAHA.114.03220

22. Yaron A, Gonen H, Alkalay I, Hatzubai A, Jung S, Beyth S, et al. Inhibition of NF-kappa-B cellular function via specific targeting of the I-kappa-B-ubiquitin ligase. EMBO J. (1997) 16:6486-94. doi: 10.1093/emboj/16.21.6486

23. Hassoun PM, Mouthon L, Barberà JA, Eddahibi S, Flores SC, Grimminger F, et al. Inflammation, growth factors, and pulmonary vascular remodeling. J Am Coll Cardiol. (2009) 54(1 Suppl):S10-19. doi: 10.1016/j.jacc.2009.04.006

24. Price LC, Wort SJ, Perros F, Dorfmüller P, Huertas A, Montani D, et al. Inflammation in pulmonary arterial hypertension. Chest. (2012) 141:210-21. doi: 10.1378/chest.11-0793

25. Jia D, He Y, Zhu Q, Liu H, Zuo C, Chen G, et al. RAGE-mediated extracellular matrix proteins accumulation exacerbates HySu-induced pulmonary hypertension. Cardiovasc Res. (2017) 113:586-97. doi: 10.1093/cvr/cvx051

26. Thenappan T, Ormiston ML, Ryan JJ, Archer SL. Pulmonary arterial hypertension: pathogenesis and clinical management. BMJ. (2018) 360:j5492. doi: $10.1136 /$ bmj.j5492

27. Tielemans B, Delcroix M, Belge C, Quarck R. TGFbeta and BMPRII signalling pathways in the pathogenesis of pulmonary arterial hypertension. Drug Discov Today. (2019) 24:703-16. doi: 10.1016/j.drudis.2018.12.001 
28. Meng XM, Nikolic-Paterson DJ, Lan HY. TGF-beta: the master regulator of fibrosis. Nat Rev Nephrol. (2016) 12:325-38. doi: 10.1038/nrneph.2016.48

29. Chelladurai P, Seeger W, Pullamsetti SS. Matrix metalloproteinases and their inhibitors in pulmonary hypertension. Eur Respir J. (2012) 40:766-82. doi: 10.1183/09031936.00209911

30. Voelkel NF, Quaife RA, Leinwand LA, Barst RJ, McGoon MD, Meldrum DR, et al. Right ventricular function and failure: report of a National Heart, Lung, and Blood Institute working group on cellular and molecular mechanisms of right heart failure. Circulation. (2006) 114:1883-91. doi: 10.1161/CIRCULATIONAHA.106.632208

31. Awad KS, Elinoff JM, Wang S, Gairhe S, Ferreyra GA, Cai R, et al. Raf/ERK drives the proliferative and invasive phenotype of BMPR2-silenced pulmonary artery endothelial cells. Am J Physiol Lung Cell Mol Physiol. (2016) 310:L187-201. doi: 10.1152/ajplung.00303.2015

32. Narayanan D, Xi Q, Pfeffer LM, Jaggar JH. Mitochondria control functional CaV1.2 expression in smooth muscle cells of cerebral arteries. Circ Res. (2010) 107:631-41. doi: 10.1161/CIRCRESAHA.110.224345

33. Kimura S, Egashira K, Chen L, Nakano K, Iwata E, Miyagawa $\mathrm{M}$, et al. Nanoparticle-mediated delivery of nuclear factor kappaB decoy into lungs ameliorates monocrotaline-induced pulmonary arterial hypertension. Hypertension. (2009) 53:877-83. doi: 10.1161/HYPERTENSIONAHA.108.121418

34. Rabinovitch M. Pathobiology of pulmonary hypertension. Extracellular matrix. Clin Chest Med. (2001) 22:433-49, viii. doi: 10.1016/S0272-5231(05)70282-3

35. Sun W, Chan SY. Pulmonary arterial stiffness: an early and pervasive driver of pulmonary arterial hypertension. Front Med. (2018) 5:204. doi: 10.3389/fmed.2018.00204

36. Bertero T, Oldham WM, Cottrill KA, Pisano S, Vanderpool RR, Yu Q, et al. Vascular stiffness mechanoactivates YAP/TAZ-dependent glutaminolysis to drive pulmonary hypertension. J Clin Invest. (2016) 126:3313-35. doi: $10.1172 /$ JCI86387

37. Thenappan T, Prins KW, Pritzker MR, Scandurra J, Volmers K, Weir EK. The critical role of pulmonary arterial compliance in pulmonary hypertension. Ann Am Thorac Soc. (2016) 13:276-84. doi: 10.1513/AnnalsATS.201509-599FR
38. Ploegstra MJ, Brokelman JGM, Roos-Hesselink JW, Douwes JM, van OschGevers LM, Hoendermis ES, et al. Pulmonary arterial stiffness indices assessed by intravascular ultrasound in children with early pulmonary vascular disease: prediction of advanced disease and mortality during 20-year follow-up. Eur Heart J Cardiovasc Imaging. (2018) 19:216-24. doi: 10.1093/ehjci/jex015

39. Hu X, Deng Y, Chen X, Zhou Y, Zhang H, Wu H, et al. Immune response of a novel ATR-AP205-001 conjugate anti-hypertensive vaccine. Sci Rep. (2017) 7:12580. doi: 10.1038/s41598-017-12996-y

40. Tissot AC, Maurer P, Nussberger J, Sabat R, Pfister T, Ignatenko S, et al. Effect of immunization against angiotensin II with CYT006-AngQb on ambulatory blood pressure: a double-blind, randomised, placebo-controlled phase IIa study. Lancet. (2008) 371:821-7. doi: 10.1016/S0140-6736(08)60381-5

41. Spohn G, Schori C, Keller I, Sladko K, Sina C, Guler R, et al. Preclinical efficacy and safety of an anti-IL- $1 \beta$ vaccine for the treatment of type 2 diabetes. Mol Ther Methods Clin Dev. (2014) 1:14048. doi: 10.1038/mtm.2014.48

42. Kündig TM, Senti G, Schnetzler G, Wolf C, Prinz Vavricka $\mathrm{BM}$, Fulurija A, et al. Der p 1 peptide on virus-like particles is safe and highly immunogenic in healthy adults. J Allergy Clin Immunol. (2006) 117:1470-6. doi: 10.1016/j.jaci.2006. 01.040

43. Vitali SH, Hansmann G, Rose C, Fernandez-Gonzalez A, Scheid A, Mitsialis SA, et al. The Sugen 5416/hypoxia mouse model of pulmonary hypertension revisited: long-term follow-up. Pulm Circ. (2014) 4:619-29. doi: 10.1086/ 678508

Conflict of Interest: The authors declare that the research was conducted in the absence of any commercial or financial relationships that could be construed as a potential conflict of interest.

Copyright (C) 2021 Dai, Qiu, Ma, Li, Chen, Song, Bai, Shi, Zheng, Pan, Liao, Liao and Zhou. This is an open-access article distributed under the terms of the Creative Commons Attribution License (CC BY). The use, distribution or reproduction in other forums is permitted, provided the original author(s) and the copyright owner(s) are credited and that the original publication in this journal is cited, in accordance with accepted academic practice. No use, distribution or reproduction is permitted which does not comply with these terms. 